IZA DP No. 7187

Happiness and Economic Growth: The Evidence

Richard A. Easterlin

January 2013 


\title{
Happiness and Economic Growth: The Evidence
}

\author{
Richard A. Easterlin \\ University of Southern California \\ and IZA
}
Discussion Paper No. 7187
January 2013

IZA
P.O. Box 7240
53072 Bonn
Germany

Phone: +49-228-3894-0

Fax: +49-228-3894-180

E-mail: iza@iza.org

Any opinions expressed here are those of the author(s) and not those of IZA. Research published in this series may include views on policy, but the institute itself takes no institutional policy positions. The IZA research network is committed to the IZA Guiding Principles of Research Integrity.

The Institute for the Study of Labor (IZA) in Bonn is a local and virtual international research center and a place of communication between science, politics and business. IZA is an independent nonprofit organization supported by Deutsche Post Foundation. The center is associated with the University of Bonn and offers a stimulating research environment through its international network, workshops and conferences, data service, project support, research visits and doctoral program. IZA engages in (i) original and internationally competitive research in all fields of labor economics, (ii) development of policy concepts, and (iii) dissemination of research results and concepts to the interested public.

IZA Discussion Papers often represent preliminary work and are circulated to encourage discussion. Citation of such a paper should account for its provisional character. A revised version may be available directly from the author. 


\section{ABSTRACT}

\section{Happiness and Economic Growth: The Evidence*}

Long term trends in happiness and income are not related; short term fluctuations in happiness and income are positively associated. Evidence for this is found in time series data for developed countries, transition countries, and less developed countries, whether analyzed separately or pooled. Skeptics, who claim that the long term time series trend relationship is positive, are mistaking the short term association for the long term one, or are misguided by a statistical artifact. Some analysts assert that in less developed countries happiness and economic growth are positively related "up to some point," beyond which the association tends to become nil, but time series data do not support this view. The most striking contradiction is China where, despite a fourfold multiplication in two decades in real GDP per capita from a low initial level, life satisfaction has not improved.

JEL Classification: I31, D60, 010, O5

Keywords: happiness, life satisfaction, subjective well-being, income, long term, short term, Easterlin paradox, developed countries, transition countries, less developed countries, China

Corresponding author:

Richard A. Easterlin

Department of Economics

KAP 318B

University of Southern California

Los Angeles, CA 90089-0253

USA

E-mail: easterl@usc.edu 
This article summarizes the current evidence on the relationship between subjective well-being and economic growth, drawing on research carried on at the University of Southern California over the last decade (see Easterlin 2005a, Easterlin and Plagnol 2008, Easterlin 2009, Easterlin et al. 2010, Easterlin and Sawangfa 2010, Easterlin et al. 2012). The focus is on the facts, that is, the evidence regarding the relationship of happiness to economic growth. Views that the empirical evidence differs from that presented here are evaluated.

The term "subjective well-being" encompasses a variety of measures of feelings of well-being - happiness, life satisfaction, ladder-of-life - which are treated here as interchangeable (cf. Easterlin 2010, pp. 8-9, 103-104, Helliwell, Layard, and Sachs 2012, ch.2). Economic growth is measured as the annual growth rate of real gross domestic product (GDP) per capita. The article takes up in succession cross section studies, the long term time series relationship, the short term time series relationship, and counterclaims to the present findings.

\section{Cross section studies}

Are happiness and economic growth positively related? Attempts to answer this question are often based on the point-of-time bivariate relation between happiness and real GDP per capita, where the basic data are mean values of these two variables for each of a wide range of countries at a given date (Veenhoven 1991, Inglehart 2002, Frey and Stutzer 2002, Diener et al. 2010). By far the most comprehensive cross section study to date is that of Angus Deaton (2008) who analyzes the 2006 Gallup World Poll data for 123 countries. Deaton's Figure 2 (Deaton 2008, p. 57) is reproduced in full here as Figure 13.1. The inference suggested by the figure is stated explicitly in Deaton's boldface title: "Each Doubling of GDP Is Associated with a Constant Increase in Life Satisfaction."

The standard measure of economic growth is that used by Deaton, real gross domestic product (GDP) per capita. The rate of growth is calculated as the percentage change in GDP per capita. Hence in graphs of SWB against GDP per capita, the latter is usually plotted on a log scale as in Deaton's figure, so that equal distances on the horizontal axis represent equal percentage changes in GDP per capita, not equal absolute increments. (An example of confusion on this score is Veenhoven 1991 p.10 who refers to the use of a logarithmic scale as "the classic trick of scales.") If one plots GDP per capita in absolute dollar values, then one observes diminishing marginal utility of income. It is this plot of happiness against GDP per capita in absolute terms that has led some analysts to state that beyond some point equal increments of GDP result in progressively smaller increments of life satisfaction. However, if GDP is plotted on a log scale as in Figure 13.1, there is no diminishing marginal utility of income in cross sectional data - equal percentage differences in GDP are associated with equal differences in happiness between countries irrespective of whether the countries are rich or poor (compare Figures 1 and 2 in Deaton's [2008] article). Indeed, based on regressions of happiness on log GDP, Deaton finds that the difference in life satisfaction associated with a doubling of GDP in cross sectional data is, if anything, greater between richer countries than between poorer countries (Deaton 2008, p. 58). 


\section{The long term time series relationship}

For real world growth rates of GDP per capita, up to, say, 10 percent per year, Deaton's boldface generalization in the title of Figure 13.1 implies that doubling the rate of economic growth over time will double the increment in life satisfaction. The cross section is, of course, describing differences among countries at a point in time, not the actual experience of a given country over time. To evaluate whether Deaton's generalization about the cross sectional relationship is supported by historical experience, I summarize here the results of several time series studies covering recent decades done by my collaborators and me. The countries included are those with a fairly long time series of comparable SWB data. For each country, the longest time span available is used - usually a minimum of 12 years but typically much more. The original time series study of happiness and economic growth (Easterlin 1974) found that, when comparing identical happiness questions, there was an increase in happiness in the United States from 1946 to 1956-67, followed by a decline to 1970, with a negligible net change over the entire twenty-four year period. This suggests that in order to ascertain the long term trend, one should aim to analyze as long a series as there is available, and the longer the series, the better.

Meaningful use of time series requires careful scrutiny of the data. Is the SWB question the same across surveys? Are the response options the same? Do the interviewer instructions change? Does the question preceding the SWB question change? Are the data nationally representative? If not, what is the nature of the geographic and population coverage? Is the population coverage fairly large? Is the coverage consistent over time? Is the time span of the data long enough so that the trend is not distorted by short term movements? An intensive effort has been made to deal with such issues in the time series data used here (see, e.g. Easterlin and Sawangfa 2010, Appendixes B and C, Easterlin 2010, pp. 20-23, 58-63, 85-87, 112-113). My collaborators and I make no claim that the resulting time series data are faultless. We have done our best, however, to examine carefully the series for each country and to make the series reasonably comparable over time (An example of a pitfall in the use of WVS data is given subsequently in the section on "Alternative Views").

For each country the average annual growth rate of real GDP per capita over the full time span of SWB data is computed, along with the corresponding average yearly change in SWB. The observations for the various countries are then compared to see whether countries with higher rates of economic growth over time have significantly higher increments in subjective well-being - at the extreme, whether doubling the growth rate of GDP doubles the increment in life satisfaction. This is, of course, only a bivariate analysis, but so too are the cross section studies, such as Deaton's, on which generalizations are based about the effect of an increase in real GDP per capita on happiness.

The results are quite consistent and easily summarized:

1. For 17 developed countries with time series ranging from 21 to 34 years, there is no significant relationship between the rate of improvement in life satisfaction and the growth rate of GDP per capita (Figure 13.2). The countries included here are fourteen developed countries of Europe plus the United States, Canada, and Australia. For most countries the long term GDP growth rates are between 1.5 and 3 per cent, but for two, Ireland and Luxembourg, the rates are between 3 and 
5 per cent. If Ireland and Luxembourg are deleted, there is still no significant relationship, as can readily be seen from a glance at Figure 13.2.

2. For 9 developing countries with time series ranging from 15 to 33 years, there is no significant relationship between the rate of improvement in happiness and the rate of economic growth (Figure 13.3). The nine countries are those with a fairly long time series on SWB. They are typically fairly populous, four in Asia, four in Latin America, and one in Sub-Saharan Africa. The economic growth rates range from around zero for South Africa to almost 10 per cent per year for China. If China, the outlier of the group, is omitted, the regression coefficient remains not significant.

3. For 11 transition countries with time series ranging from 12 to 22 years, there is no significant relationship between the improvement in life satisfaction and the rate of economic growth (Figure 13.4). The eleven countries range across central and eastern Europe and are those for which there is a life satisfaction observation near the start of the transition (the early life satisfaction observation is essential, cf. Easterlin 2009, p. 132, and the discussion of Figs. 13.9 and 13.13 below). The economic growth rates of the 11 countries range from slightly negative to about 3 per cent per year.

4. For all 37 countries taken together, with time series ranging from 12 to 34 years in length, there is no significant relation between the improvement in life satisfaction and the rate of economic growth (Figure 13.5). The growth rates of GDP per capita typically range from slightly negative to almost 6 per cent per year. If the one outlier, China, is omitted, the regression coefficient is still not significant.

In sum, for rich, developing, and transition countries, whether pooled or analyzed separately, there is no time series evidence that a higher economic growth rate increases the rate of improvement in life satisfaction. Doubling the rate of economic growth does not double the increase in life satisfaction; rather, the evidence is that it has no significant effect at all. The contrast between the positive cross sectional relation and the long term nil relation, demonstrates the well-known happiness-income (or Easterlin) paradox (Easterlin et al. 2010). It also makes clear that the cross sectional relationship is no guide to actual historical experience.

Reasonably comparable time series data on SWB in less developed countries are in short supply. In the foregoing analysis, the World Values Survey (WVS) was the principal source and only nine less developed countries were available with reasonably long and comparable data over time. Fortunately the annual Latinobarometer surveys, covering 17 Latin American countries since 1994, provide a new and additional body of data on the experience of less developed nations. The life satisfaction question in the Latinobarometer surveys changes too frequently to be used, but the question on financial satisfaction is the same from 1994 to 2006: "How would you define, in general, the current economic situation of yourself and your family? Would you say that it is.....

$1=$ Very bad; 2=Bad; 3=Regular; 4=Good; 5=Very Good"

One would expect that the responses to this question would be even more closely linked to economic growth than those on life satisfaction, because the central feature of economic growth is a rapid increase of real incomes, and such an increase would 
presumably lead directly to greater satisfaction with one's financial situation. Hence, one might expect that countries with higher growth rates of real GDP per capita would have greater increments in financial satisfaction.

In fact, there is no evidence that a greater increase in financial satisfaction accompanies more rapid economic growth. As in the analysis of the WVS data, the regression line fitted to the Latin American data indicates a nil relationship (Figure 13.6). The results from the Latinobarometer buttress those from the World Values Survey.

If there is any less developed country for which one would expect a positive impact of economic growth on SWB it is China, whose growth since 1990 from an initially very low value has been at the highest rate ever recorded, a four fold multiplication of real GDP per capita in two decades (Heston, Summers, and Aten 2012). Household appliances such as refrigerators and washing machines - quite rare in 1990 are now commonplace in urban areas (OECD 2010a). Color television sets currently average over one per household. By 2008, almost one in ten urban households owned a car and China had become the world's leading automobile producer (OECD 2010b).

Yet, the combined evidence from six SWB surveys is that life satisfaction in China has not improved, and, if anything, may have declined somewhat (Easterlin et al. 2012). Life satisfaction appears to have followed a U-shaped trajectory, bottoming out in the first part of this millennium; the recovery since then has left SWB somewhat short of its 1990 level (Figure 13.7).

The six surveys in Figure 13.7 vary in their comprehensiveness. In general, they are more representative of urban areas, but, then, income growth was much higher in urban areas (Chinese Academy of Social Sciences 2011). If economic growth has a strong positive effect on SWB, one would expect that in a two-decade period of more than fourfold growth of real per capita income, any sizable impact on SWB would be picked up in most of these surveys. Yet, all but one fail to give any indication of a marked increase of the type one would expect based on the cross section results.

The one exception in Figure 13.7 is the PEW survey. But in this survey the initial observation falls at the economic trough, and the subsequent increase captures the recovery segment of the $\mathrm{U}$. This is evident from comparison with the other surveys in Figure 13.7. It is also apparent from data in the PEW survey itself. Among other things, respondents were asked, "Now thinking about our economic situation, how would you describe the current economic situation in China? Is it very good, somewhat good, somewhat bad, or very bad?" Here are the responses to this question, along with the survey values for mean life satisfaction in 2002 and 2010:

$\begin{array}{lll}\text { Year } & \begin{array}{l}\text { Economic situation }(\% \\ \text { somewhat or very good })\end{array} & \begin{array}{l}\text { Mean life } \\ (\text { scale 0-10) }\end{array} \\ 2002 & 52 & 5.27 \\ 2010 & 93 & 5.85\end{array}$

Clearly the increase in life satisfaction in China reported in the PEW survey occurs in conjunction with a marked improvement in the economy.

\section{The short term time series relationship}

The PEW data illustrate a widely observed relationship, namely, that in the short term happiness goes up and down with the state of the economy. This relationship has 
been demonstrated for a group of developed countries by DiTella, MacCulloch, and Oswald (2001). It is illustrated here for the developed bloc by the recent experience of the United States, where the Great Recession has brought happiness to the lowest level ever recorded in the General Social Survey (Figure 13.8, see also Deaton 2011). Microeconomic equations consistently show that unemployment has a significant and sizable negative impact on happiness (Frey and Stutzer 2002, Layard 2005, Oswald 1997). The recent United States experience provides a dramatic illustration.

The short term positive association between happiness and GDP holds also in the transition countries. The U-shaped pattern of life satisfaction in China's transition seen above corresponds to the rise and fall of the unemployment rate there (Easterlin et al. 2012). Similar U-shaped movements are apparent in transition countries in Europe for which the time series data encompass the onset of the transition. Figure 13.9 presents life satisfaction and GDP data for three of these transition countries (for others, see Easterlin 2009, pp. 88-91). The timing of the movements in life satisfaction and GDP is closest for the GDR, where there are annual data for both series. For Estonia and the Russian Federation, for which only intermittent life satisfaction data are available, one finds both life satisfaction and GDP with similar U-shaped changes. If the GDP observations are confined to those dates for which only the intermittent life satisfaction data are available, the timing pattern becomes even more similar. The synchronous short-term U-shaped movement of both life satisfaction and GDP is typical of the European transition countries. If trend lines are fitted that span both the contraction and expansion periods, the long term relationship is typically nil, in contrast to the short term positive relationship (see Easterlin 2010, p. 100). Some analysts, who use data that do not include the initial contraction phase of the transition mistakenly take the positive happinessincome relation in the recovery period as indicative of the long-term trend (Frijters et al. 2004, Guriev and Zhuravskaya 2009, Sanfey and Teksoz 2007).

The short term positive association of happiness and income is found also in the developing countries. It is evidenced here in the Latinobarometer data used in Figure 13.6 above, the best less developed country data for short term analysis because they are yearly. For both financial satisfaction and GDP, OLS trend lines were fitted to the full time span of data available for each country. The deviation at each date of the actual value from the trend value was then computed. For each country one typically finds that when GDP is above trend, financial satisfaction is above trend; when GDP is below trend, financial satisfaction is below - in short, that in each country deviations from trend for financial satisfaction and GDP are significantly positively related (Easterlin et al. 2010, Figure 3). Moreover, when one compares the seventeen countries, the deviations exhibit a synchronous movement. In a year when one country is below trend, almost all of the others are; similarly, almost all countries are above trend at the same time. Figure 13.10 presents for both financial satisfaction and GDP the mean of the deviations for the seventeen countries in each year. The GDP time series of mean deviations exhibits a clear pattern of collapse and recovery over the period, reflecting the world crisis precipitated by the Asian financial crisis of 1997 followed by the 1998 Russian crisis. The latter especially affected commodity prices and had a great impact throughout Latin America. What is noteworthy is that for financial satisfaction the time series of mean deviations exhibits a fairly similar movement of collapse and recovery to that for GDP. Clearly in this group of developing countries financial satisfaction and GDP are 
positively related in the short term. The general conclusion of this section, based on evidence for developing, transition, and developed countries, is that in the short term, happiness and economic growth are positively related. Economic contractions and recoveries induce corresponding movements in happiness.

Reconciling the short term and long term relationship - In the short term happiness and income are positively related; in the long term the relationship is nil. Figure 13.11 illustrates how it is possible for these seemingly disparate patterns to exist. The solid lines illustrate the (assumed) actual time series movement of happiness $(\mathrm{H})$ and income (Y). The dotted vertical lines set off expansions and contractions. These lines show how trough-to-peak ( $\mathrm{t}-\mathrm{p})$ and peak-to-trough movements ( $\mathrm{p}-\mathrm{t})$ in both happiness and income are synchronous and positively related. The broken lines trace the long term trends in happiness and income, and demonstrate that the happiness trend remains flat despite the upward trend in income. Fluctuations in happiness and income (the short term movement) go together, but the trends in happiness and income (the long term movement) do not.

\section{Alternative Views}

Cross section evidence - Two types of evidence - cross section and time series - are claimed to contradict the findings reported above. The reasoning regarding the cross section evidence is directed at the happiness-income paradox, and appears to be as follows. If, at a point in time, happiness and GDP per capita are positively related among countries, then the time series finding of no relation must be wrong - the higher income countries must have experienced at some time in the past an increase in life satisfaction in conjunction with rising real income per capita (Arrow and Dasgupta 2009, Bok 2010, Guriev and Zhuravskaya 2009). Cross section evidence is also cited in this vein in the Stiglitz-Sen-Fitoussi report (2009).

To say the least, this argument is puzzling. First of all, if economic growth raised life satisfaction at some time in the past, one would expect to find evidence of this effect in current time series for middle- or lower-income countries. Yet, as the data presented here demonstrate, there is no evidence of such an effect, China being the most recent and striking example. Second, the argument assumes that the data demonstrate a causal relationship, in which GDP is the cause of differences in happiness among countries. The possibility that some other factor(s) such as public policy might account for the happiness differences is not even considered (cf. Easterlin 2013). Finally, the essential meaning of "paradox" is the seeming contradiction between the first and second terms of the paradox - in this case, between the cross section and time series results. That scholars would cite cross sectional results as disproving the time series finding is to ignore the very meaning of paradox. If there were no positive relation in the cross section, there would be no paradox! The cross section does not disprove the time series, any more than the time series disproves the cross section. The challenge is to develop an explanation that reconciles these seemingly contradictory empirical findings (for examples, see Clark et al. 2008, Easterlin 2010, chs. 1, 2, 5).

Time series evidence - Time series studies claiming that the relationship between happiness and income is, in fact, positive are a more direct challenge, especially because the underlying data in such studies typically overlap considerably with those used here. One of the first such studies was an article by Hagerty and Veenhoven (2003). This has 
been critiqued by Easterlin (2005b) who pointed out, among other things, the lack of statistical significance of their results. This criticism has been acknowledged by Hagerty and Veenhoven to be correct (Hagerty and Veenhoven 2006).

An article by Ronald Inglehart and his collaborators (2008) concludes that the life satisfaction and happiness measures in the WVS reflect different determinants, the former, economic conditions, and the latter, political circumstances. They argue that "many ex-communist countries experienced democratization accompanied by economic collapse, resulting in rising happiness and falling life satisfaction" (p. 277). Their conclusion that falling life satisfaction accompanied deteriorating economic conditions is consistent with the short-term positive happiness-income relation in transition countries described above. However, their inference that happiness followed a different course, reflecting improved political conditions, is at variance with the view expressed earlier that happiness and life satisfaction are similar concepts; hence they should change similarly over time.

The explanation of the seemingly disparate finding for happiness by Inglehart et al is that it is a statistical artifact, illustrating the point made earlier about the need to study time series data carefully. The upward trend in happiness that they report results from a "primacy bias" in the happiness data due to a change in instructions to the interviewers between adjacent waves of the survey data that they use. In wave 2, interviewers were instructed to alternate the order of response choices from one respondent to the next. Thus respondent 1 would be presented with choices ranging from "very happy" down to "not at all happy," while respondent 2 would be presented with "not at all happy" first. There are a number of survey studies demonstrating a tendency for respondents to favor earlier over later choices (Belson 1966, Chan 1991, Schuman and Presser 1981). In wave 2, therefore, half of the respondents would have been more inclined towards less happy choices, by virtue of being presented with the more negative options first. In wave 3, however, the "very happy" option appears first, and the instruction to alternate response options no longer appears. Hence happiness responses in this wave would tend to be biased upward relative to the preceding wave. No such change in instructions occurs in regard to the life satisfaction data, and this is why the life satisfaction data are relied on here in Figures 13.2-13.5.

In fact, there is evidence from South Africa's experience that life satisfaction and happiness move very similarly in conjunction with democratization. In May 1994, one month after the country's first democratic election, a survey was conducted that included questions about both happiness and life satisfaction. Table 13.1 presents for both measures the percentage of the black population in the top two (out of five) categories at that time, and the corresponding percentage at the two adjacent dates when similar surveys were conducted. Note how by both measures the well-being of blacks soared around the time of the election. But as noted sociologist Valerie Møller, who was responsible for the collection of these data, observes: "[P]ost-election euphoria was short lived. Satisfaction levels have since returned to ones reminiscent of those under the former regime" (Møller 2007). This return is registered by both SWB measures. Moreover, the magnitude of rise and fall is virtually identical for the two measures. This is striking evidence of the tendency for happiness and life satisfaction to move together, not differently, in response to a major change in political conditions. 
A recent article by Diener et al. (2012) using Gallup World Poll data reports a positive time series relation between life satisfaction and GDP per capita, which, in the view of the authors, contradicts the Easterlin paradox. The data that they use, however, covers only a six-year period - two short to test the Easterlin paradox, and obviously dominated by the short term association between happiness and income.

The most widely-cited study claiming to contradict the findings reported here of a nil happiness-income relationship in the long term is that by Stevenson and Wolfers (2008). The recent update of this article, Sacks, Stevenson, and Wolfers 2012 (henceforth S-S-W 2012), is cited in the Helliwell et al World Happiness Report (2012) as having "powerfully challenged" the present conclusion about the long-term relationship. According to the World Happiness Report, S-S-W show that, "both in countries covered by the World Values Survey and in those covered by the Eurobarometer, there has been an increase in life satisfaction over recent decades" (2012, p. 65). In fact, as will be shown in what follows, both the WVS and Eurobarometer results of S-S-W reflect the short-term, not the long-term relationship.

In regard to the WVS, the S-S-W analysis is based only on waves 1 through 4 (for most countries, actually waves 2 to 4 ), and the regression results rely heavily on outlier observations for the transition countries that reflect the short term relationship. It is not clear why wave 5 of the WVS, which became available as early as 2008 , is not used in their 2012 study. It is used in the regressions presented here in Figures 13.2-13.5, and also in the Easterlin and Sawangfa analysis, published in 2010. As for the Eurobarometer, S-S-W replace long-period time series data with shorter-period segments that reflect the short term relationship of happiness to income. Thus, in their Eurobarometer analysis, they go in the exact opposite direction from the stricture suggested above, to use the longest time series available.

As shown in Figure 13.9 above, the typical pattern of life satisfaction in the transition from socialism to capitalism is U-shaped. If the time span of a country's WVS series for life satisfaction fails to capture both the contraction and expansion segments of the $U$, as is often the case when only WVS waves 2 to 4 are studied, then the short-term relation is likely to be observed rather than the long-term relation.

The WVS data for the Russian Federation analyzed by S-S-W provide an example. As is clear from Figure 13.12, life satisfaction in Russia describes the typical transition pattern over the period 1990-2005, the time span used for the Russian Federation in Figures 13.4 and 13.5 above. S-S-W, however, confine their analysis to waves 2 thru 4, the shaded area in Figure 13.12. Their time span is thus largely restricted to the contraction phase of the Russian Federation's transition, and consequently they observe large negative changes in both life satisfaction and GDP (S-S-W 2012, Figure 6 ). If they had included wave 5, they would have found, instead, the relationship plotted in Figure 13.4 here, a positive change in life satisfaction associated with a slightly negative change in GDP. The S-S-W result for the Russian Federation based on WVS waves 2 and 4 is representative of that for several other transition countries - Latvia, Lithuania, and Belarus - all of which are outliers in S-S-W's Figure 6, and contribute importantly to their statistical result of a positive regression relationship between growth and happiness.

Slovenia is an example of a transition country in which only the expansion phase of the transition is captured in the WVS life satisfaction data. For this reason it is 
excluded from the analysis in Figures 13.4 and 13.5 above; however, S-S-W include Slovenia. As shown in Figure 13.13, the wave 2 survey of life satisfaction in Slovenia occurred at the trough of the $U$; and the subsequent movement from wave 2 to wave 4 spans the expansion phase of the transition. Consequently, in the S-S-W regression analysis Slovenia appears as an outlier with a large positive change in both life satisfaction and GDP. As in the case of the Russian Federation, S-S-W are again capturing the short run, not long run relation of happiness to income. It is short run changes such as these that largely explain the positive time series relationship in the WVS reported by S-S-W.

S-S-W's positive regression result is also partly due to two other outlier observations, whose importance in determining the regression result S-S-W specifically acknowledge:

There are also some interesting outliers.... Korea, for example, had only a modest change in subjective well-being and a very large increase in GDP [it is off-scale in their Figure 6]. Hungary experienced very little growth, but had a serious decline in life satisfaction. In the regression results reported below, we include these countries, but it is clear that excluding them would change our estimates (S-S-W 2012, p. 79).

Hungary is, of course, a transition country, and the time span of S-S-W's analysis is dominated by the contraction phase of the transition there. Korea's "modest change" in SWB is due entirely to a low value for life satisfaction in 1982 and is probably the result of a bias caused by the survey's timing. The 1982 survey was conducted only a few months after the assassination of the country's president. Subsequent observations for Korea, from 1990 to 2005, reveal no improvement in life satisfaction despite the continuation of a very high growth rate of GDP per capita, about 5 per cent per year. SS-W's analysis excludes the 2005 WVS wave 5 observation for Korea, but even between waves 2 and 4 (1990 to 2001) there is no improvement in Korea's life satisfaction.

Taken as a whole, the WVS analysis by S-S-W illustrates the relevance of the statement made earlier: meaningful use of time series requires careful scrutiny of the data. This does not mean that the data must be nationally representative as they assert. In some cases we use here series with about 70 per cent population coverage, but we have checked that the survey coverage remains reasonably consistent over time and that the population covered would be that expected to benefit from economic growth (cf. Easterlin and Sawangfa 2010, Appendices B and C).

Turning to S-S-W's Eurobarometer analysis, the positive association that S-S-W report between changes in happiness and income is again based on short term changes. Ireland provides an example. In the regression for 17 developed countries shown in Figure 13.2 above, Ireland has the highest growth rate of GDP per capita, but only an average rate of change in SWB. In analyzing essentially the same data for Ireland, S-SW replace the long term change from 1973 to 2007 of Figure 13.2 by three shorter period movements (S-S-W 2012, pp. 82-84). Figure 13.14 reproduces Figure 13.2 with the three sub-period observations for Ireland replacing the single 1973-2007 observation in Figure 13.2 .

As can be seen, if one replaces the full period observation by the three sub-period observations it would tend to tilt the regression line in a positive direction. This tilt is illustrated by the broken line connecting the three points for Ireland in Figure 13.14. The 
earliest S-S-W observation, that labeled 78-87, spans a period in which the economy plunged into a major recession - the economic growth rate is among the lowest and the rate of change in SWB is negative. The subsequent recovery observations (labeled by SS-W, 88-98 and 98-05) yield values of high economic growth coupled with positive increments in life satisfaction. The three points together make for a positively-sloped regression line. For all of the Eurobarometer countries included in their analysis, S-S-W similarly replace the long term change with shorter term changes. After doing this, their fitted regression line is tilted moderately in a positive direction. Based on this tilt, they report that the "estimated satisfaction-income gradient resulting from these long-run differences is marginally statistically significant at 0.28 " (S-S-W, p. 84 , emphasis added). From this, it appears that even their shorter term observations are not short enough to produce a statistically acceptable positive regression relationship.

\section{Conclusion}

The question posed at the start of this article was whether the facts indicate that economic growth leads to increased happiness. The answer suggested by the evidence surveyed - 17 developed countries, 9 developing countries, 11 transition countries, 17 Latin American countries, and China - is, no. Contrary conclusions are due to analysts confusing the short-term (positive) relation of SWB and GDP with the long-term (nil) relation, or to a statistical artifact.

The evidence also indicates that the frequently cited positive cross section relation of happiness to income is not reproduced in time series, where the long term relation tends to be nil. Nor is there evidence in time series, such as that for China, that in low income countries economic growth raises happiness "up to some point," beyond which growth has no further effect.

Keywords: Happiness, life satisfaction, subjective well-being, economic growth, income, long term, short term, Easterlin paradox, developed countries, transition countries, less developed countries, China.

\section{Acknowledgements}

I am grateful to Robson Morgan, Kelsey O'Connor, and Malgorzata Switek for helpful comments, and to the University of Southern California for financial support. 


\section{References}

Arrow, K.J., Dasgupta, P.S. (2009). Conspicuous Consumption, Inconspicuous Leisure. The Economic Journal, 119(541), F500,F513.

Belson, W.A. (1966). The Effects of Reversing the Presentation Order of Verbal Rating Scales. Journal of Advertising Research, 6(4), 30-37.

Bok, D. (2010). The Politics of Happiness: What Government Can Learn from the New Research on Well-Being. New Jersey: Princeton University Press.

Chan, J.C. (1991). Response-Order Effects in Likert-type Scales. Educational and Psychological Measurement, 51(3), 531-40.

Chinese Academy of Social Sciences (2011). Blue Book of China's Society: Society of China Analysis and Forecast (in Chinese). China: Social Sciences Academic Press.

Clark, A.E., Frijters, P., Shields, M.A. (2008). Relative Income, Happiness, and Utility: An Explanation for the Easterlin Paradox and Other Puzzles. Journal of Economic Literature, 46(1), 95-144.

Deaton, A. (2008). Income, Health, and Well-Being around the World: Evidence from the Gallup World Poll. Journal of Economic Perspectives, 22(2), 53-72.

Deaton, A. (2011). The Financial Crisis and Well-Being of Americans. National Bureau of Economic Research Working Paper 19128.

Diener, E., Ng, W., Harter, J., Arora, R. (2010). Wealth and happiness across the world: Material prosperity predicts life evaluation, whereas psychosocial prosperity predicts positive feeling. Journal of Personality and Social Psychology, 99, 52-61.

Diener, E., Tay, L., Oishi, S. (2012). Rising Income and the Subjective Well-Being of Nations. Journal of Personality and Social Psychology, advance online publication. doi:10.1037/a0030487.

DiTella, R., MacCulloch, R.J., Oswald, A.J. (2001). Preferences over Inflation and Unemployment: Evidence from Surveys of Happiness. American Economic Review, 91(1), 335-341.

Easterlin, R.A. (1974). Does Economic Growth Improve The Human Lot? In P.A. David, M.S. Reder, Essays in Honour of Moses Abramovitz (pp. 89-125).

Massachusetts: Academic Press.

Easterlin, R. A. (2005a). Diminishing Marginal Utility of Income? Caveat Emptor, Social Indicators Research, 70(3), 243-55. 
Easterlin, R.A. (2005b). Feeding the Illusion of Growth and Happiness: A Reply to Hagerty and Veenhonven. Social Indicators Research, 74(3), 429-43.

Easterlin, R.A. (2009). Lost in Transition: Life Satisfaction on the Road to Capitalism. Journal of Economic Behavior and Organization, 71(2), 130-145.

Easterlin, R.A. (2010). Happiness, Growth, and the Life Cycle. New York: Oxford University Press.

Easterlin, R.A. (2013) Happiness, Growth and Public Policy, Economic Inquiry, 51(1), 1-15.

Easterlin, R.A., McVey, L.A., Switek, M., Sawangfa, O., Zweig, J.S. (2010). The Happiness Paradox Revisited. Proceedings of the National Academy of Sciences, 107:22463-22468.

Easterlin, R. A., Plagnol, A. (2008). Life Satisfaction and Economic Conditions in East and West Germany Pre- and Post-Unification, Journal of Economic Behavior \& Organization, 68(3), 433-44.

Easterlin, R.A., Sawangfa, O. (2010). Happiness and economic growth: Does the cross section predict time trend. In E. Diener, J.F. Helliwell, D. Kahneman (Eds.) International Differences in Well-Being (Appendixes B and C). New York: Oxford University Press.

Easterlin, R.A., Morgan, R., Switek, M., Wang, F. (2012). China's Life Satisfaction, 1990-2010. Proceedings of the National Academy of Sciences, 109 (25), 9775-9780.

Frey, B.S., Stutzer, A. (2002). Happiness and Economics: How The Economy and Institutions Affect Well-Being. New Jersey: Princeton University Press.

Frijters, P., Haisken-DenNew, J.P., Shields, M.A. (2004). Money Does Matter! Evidence from Increasing Income and Life Satisfaction in East Germany Following Reunification. American Economic Review, 94(3): 730-740.

Guriev, S., Zhuravskaya, E. (2009). (Un)happiness in Transition. Journal of Economic Perspectives, 22(2), 152.

Hagerty, M.R., Veenhoven, R. (2003). Wealth and Happiness Revisited - Growing National Income Does Go with Greater Happiness. Social Indicators Research, 64(1), 1-27.

Hagerty, M.R., Veenhoven, R. (2006). Rising Happiness in Nations 1946-2004: A

Reply to Easterlin. Social Indicators Research, 79(3), 421-436. 
Helliwell, J.R., Layard, R., Sachs, J. (2012) World Happiness Report. New York: United Nations

Heston, A., Summers, R., Aten, B. (2012) Penn World Table Version 7.0. Center for International Comparisons of Production, University of Pennsylvania.

https://pwt.sas.upenn.edu/php_site/pwt_index.php.

Inglehart, R.F. (2002) Globalization and Postmodern Values. The Washington Quarterly, 23(1), 215-228.

Inglehart, R., Foa, R., Peterson, C., Wetzel, C. (2008). Development, Freedom, and Rising Happiness: A Global Perspective (1981-2007). Perspectives on Psychological Science, 3(4), 264- 285.

Layard, R. (2005) Happiness: Lessons from a New Science. London: Penguin Press.

Møller, V. (2007). Researching quality of life in a developing country: lessons from the South African case. In I. Gough, J.A. McGregor (Eds.), Wellbeing in Developing Countries: From Theory to Research (pp. 242-258). Cambridge: Cambridge University Press.

NORC (2010) General Social Survey, available at:

http://www3.norc.org/GSS+Website/

OECD (2010a). China in the 2010s: Rebalancing Growth and Strengthening Social Safety Nets. Beijing: OECD.

OECD (2010b). OECD Economic Surveys: China, Vol. 2010/6. Beijing: OECD.

Oswald, A.J. (1997). Happiness and Economic Performance. The Economic Journal, $107(445), 1815-1831$.

Sacks, D.W., Stevenson, B., Wolfers, J. (2012) Subjective well-being, income, economic development, and growth." In P. Booth (Eds) ... and the Pursiut of Happiness: Well-Being and the Role of Government. London: The Institute of Economic Affairs.

Sanfey, P., Teksoz, U. (2007). Does Transition Make You Happy? Economics of Transition, 15(4), 707-731.

Schuman, H., Presser, S. (1981). Questions and Answers in Attitude Surveys: Experiments on Question Form, Wording and Context. Massachusetts: Academic Press. 
Stevenson, B., Wolfers, J. (2008). Economic Growth and Subjective Well-Being:

Reassessing the Easterlin Paradox. Brookings Papers on Economic Activity, 2008(Spring):1-87.

Stiglitz, J.E., Sen, A., Fitoussi, J.P. (2009). Report of the Commission on the Measurement of Economic Performance and Social Progress. http://www.stiglitz-senfitoussi.fr/en/index.htm.

Veenhoven, R. (1991). Is happiness relative? Social Indicators Research. 24, 1-34. 


\section{Figures}

Figure 13.1. Each Doubling of GDP is Associated with a Constant Increase in Life

\section{Satisfaction}

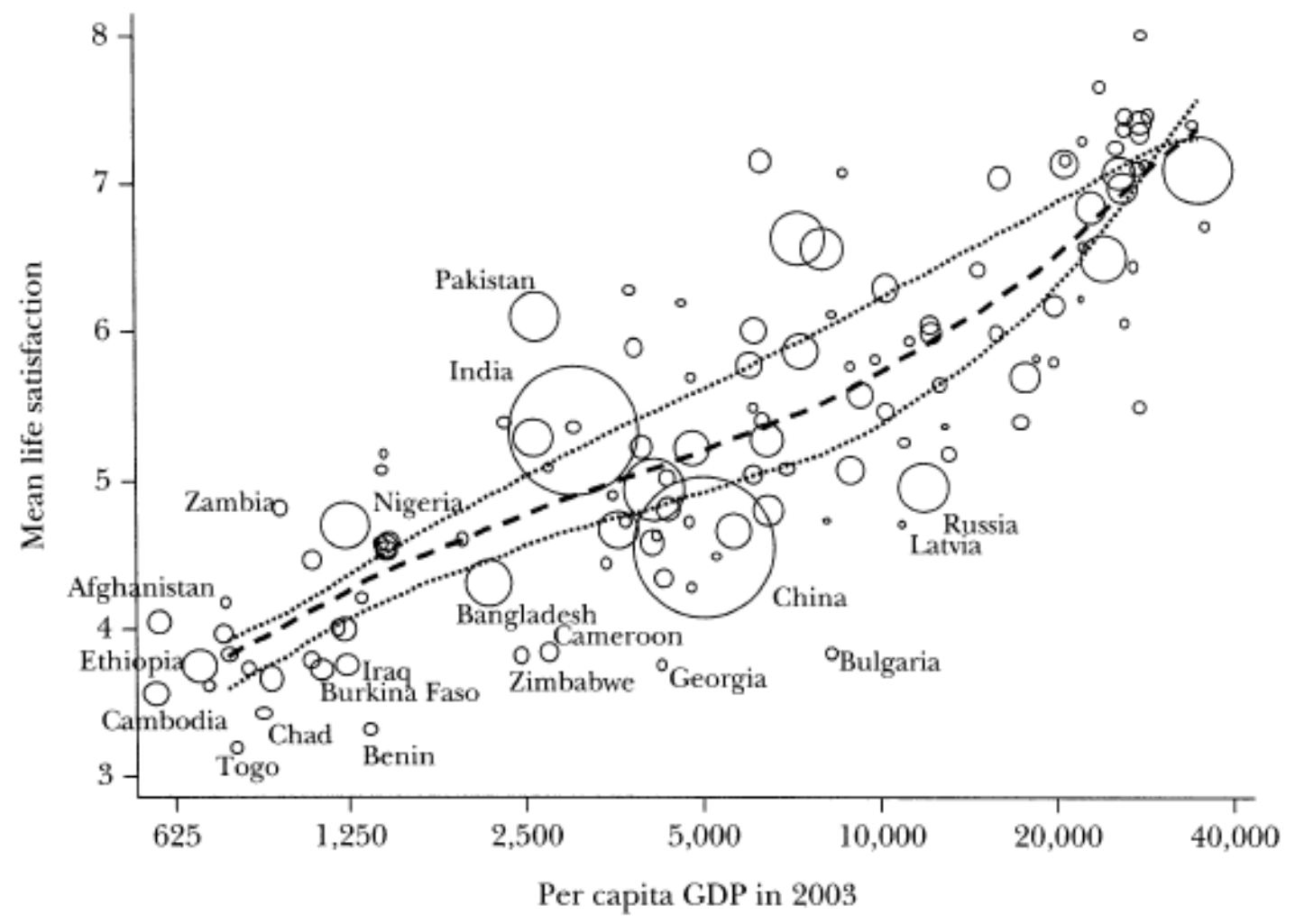

Source: The figure and bold-face title are reproduced in full from Deaton 2008, 57. The cross section data are for 2006 and each circle is a country with diameter proportional to population. 
Figure 13.2. Growth Rate of Life Satisfaction and Real GDP per Capita, 17 Developed Countries

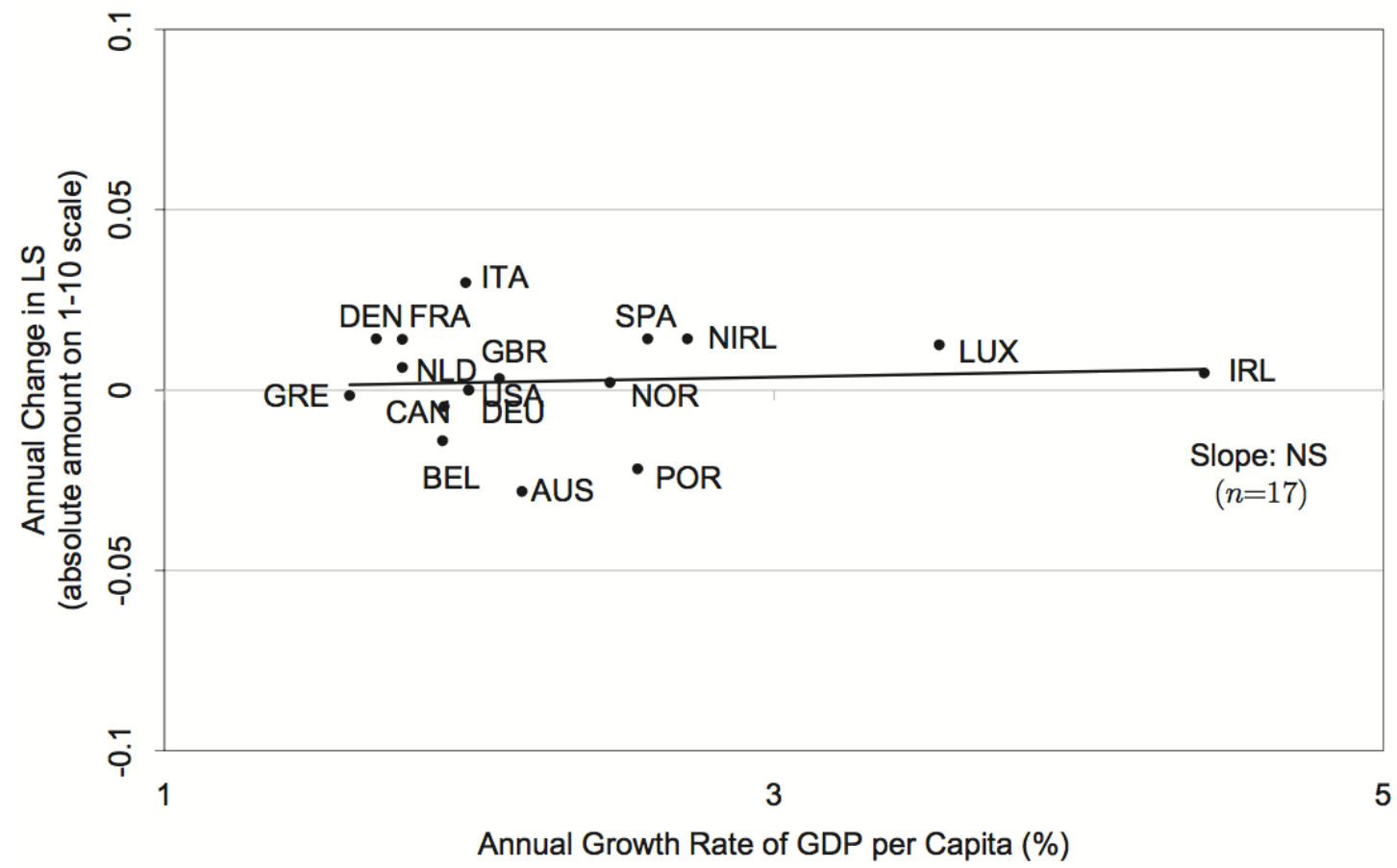

Source: Easterlin et al. 2010, Table S2. NS here and in subsequent figures signifies that the slope of the regression line is not significantly different from zero. The time spans of the country growth rates are for periods ranging from 21 to 34 years. 
Figure 13.3. Growth Rate of Life Satisfaction and Real GDP per Capita, 9 Developing Countries

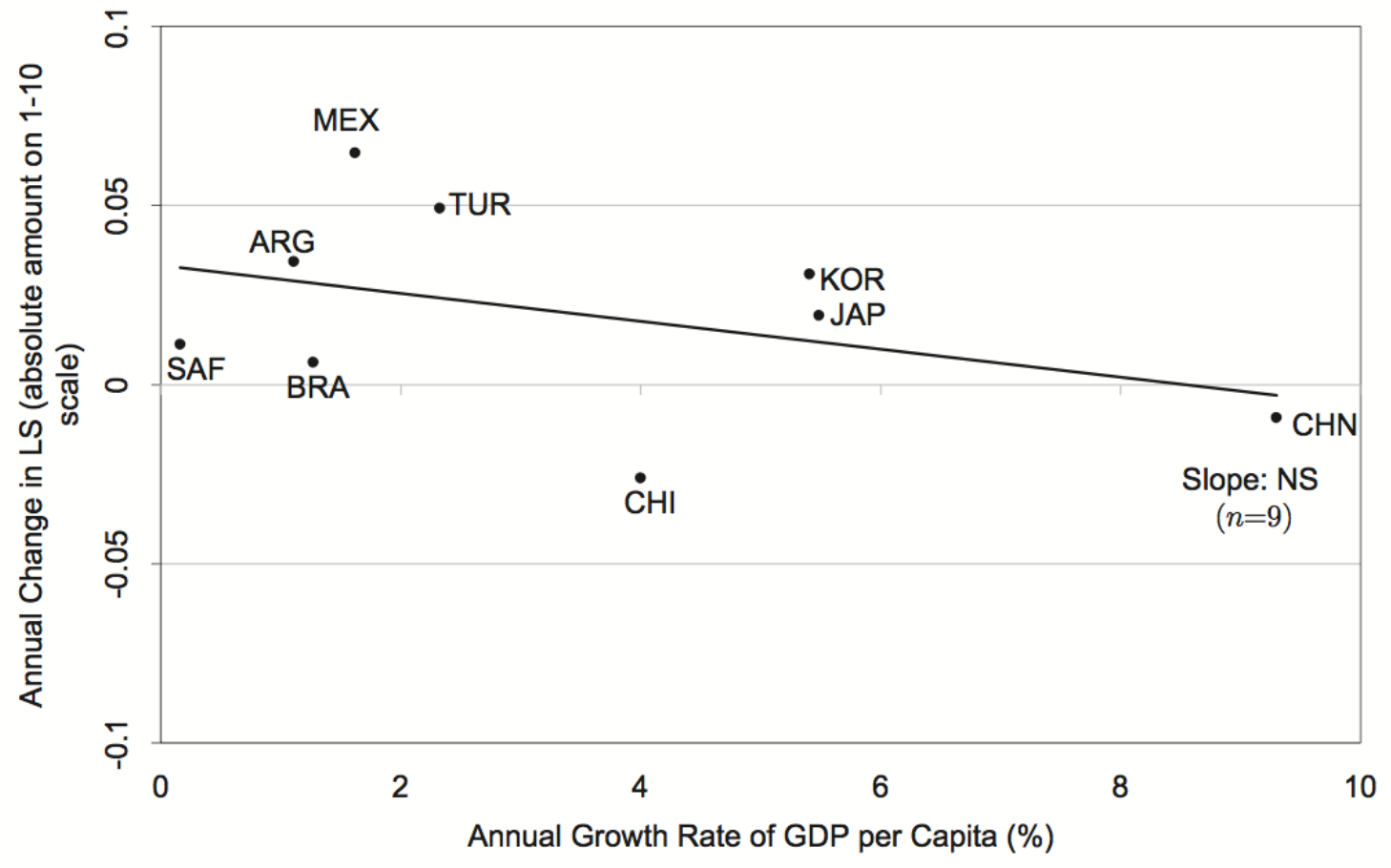

Source: See Figure 13.2. The time spans of the country growth rates are for periods ranging from 15 to 33 years. 
Figure 13.4. Growth Rate of Life Satisfaction and Real GDP per Capita, 11 Transition Countries

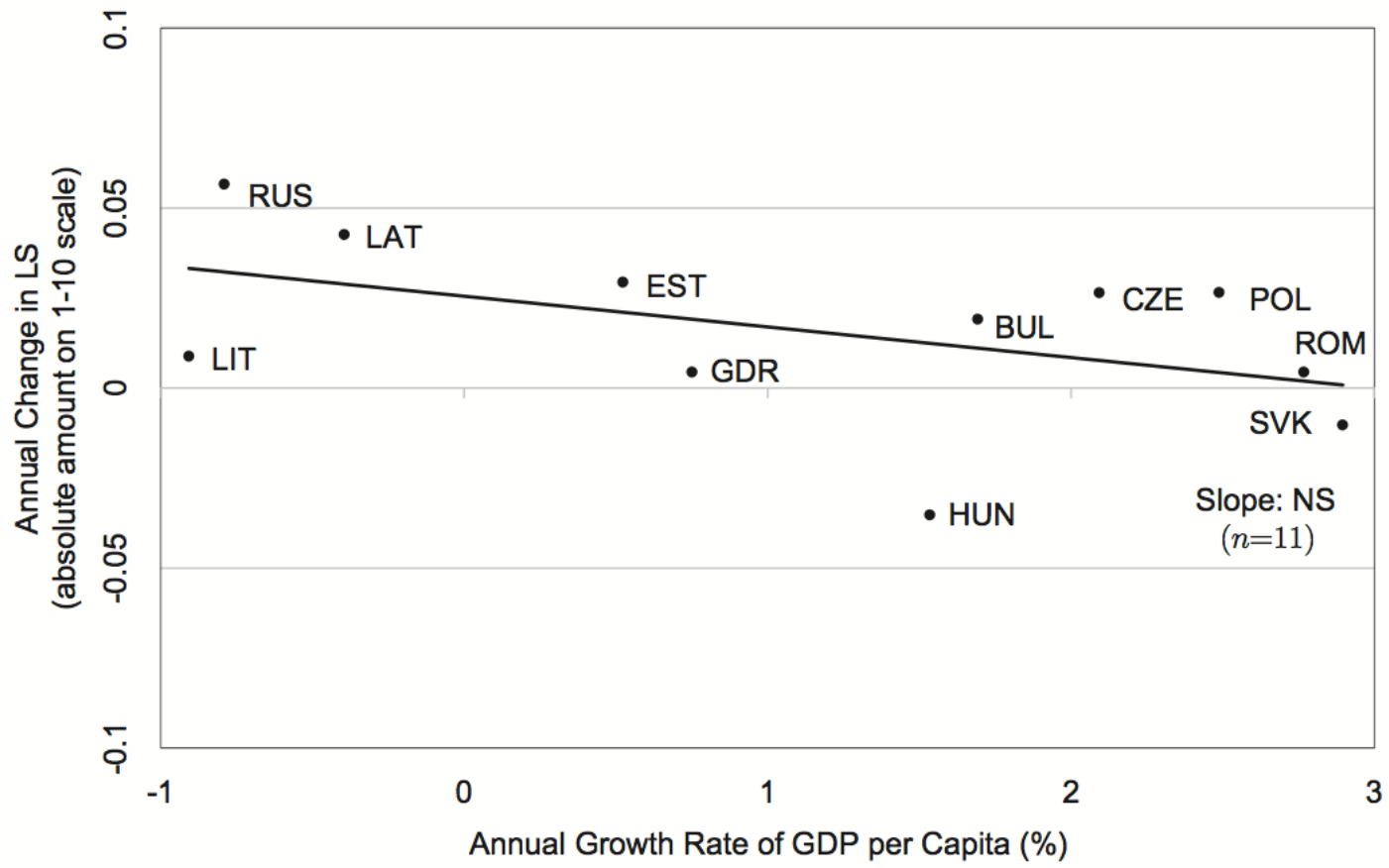

Source: See Figure 13.2. The time spans of the country growth rates are for periods ranging from 12 to 22 years. 
Figure 13.5. Growth Rate of Life Satisfaction and Real GDP per Capita, 17 Developed,

11 Transition, and 9 Developing Countries

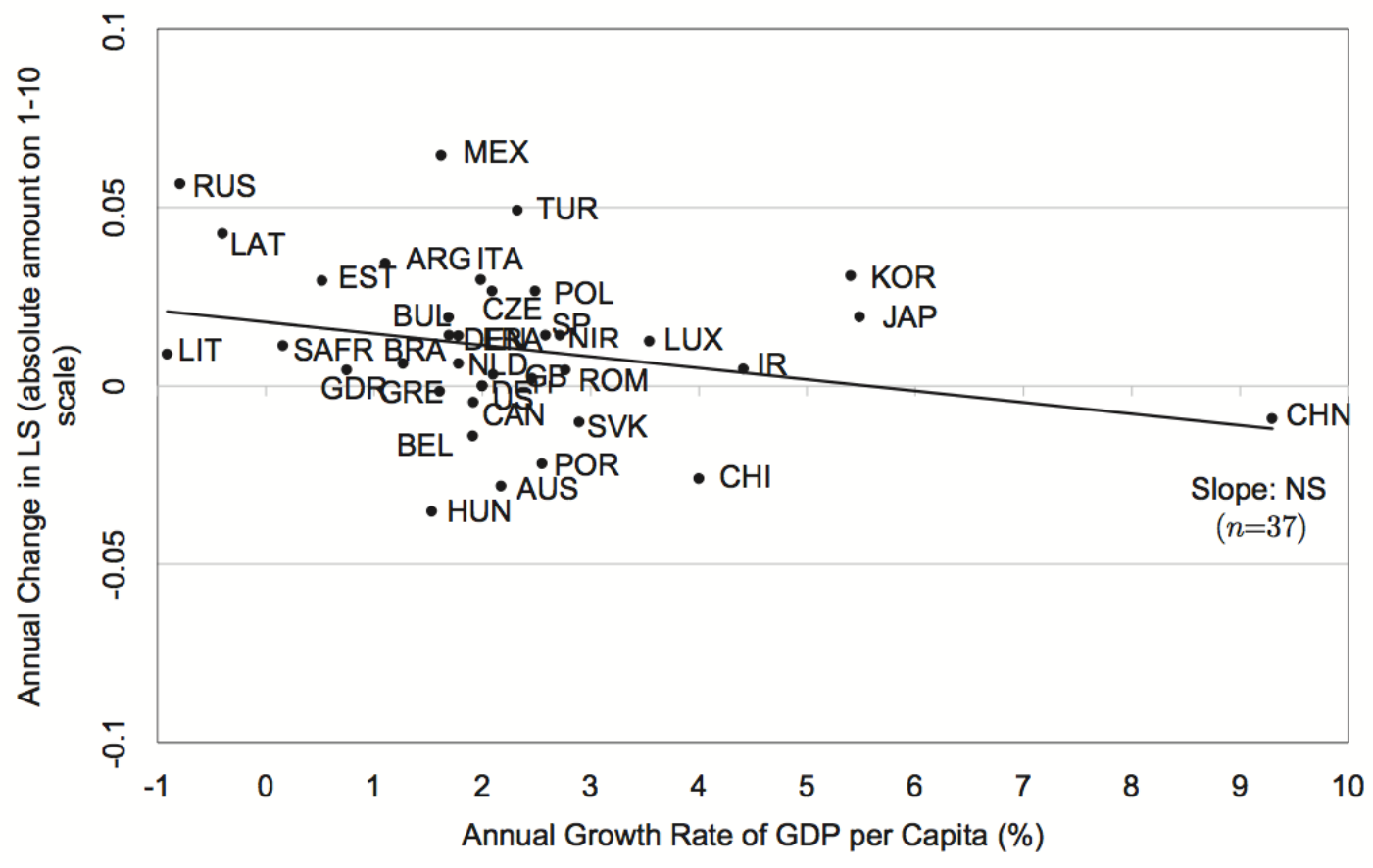

Source: See Figure 13.2. The time spans of the country growth rates are for periods ranging from 12 to 34 years. 
Figure 13.6. Growth Rate of Financial Satisfaction and Real GDP per Capita, 17 Latin American Countries, 1994-2006

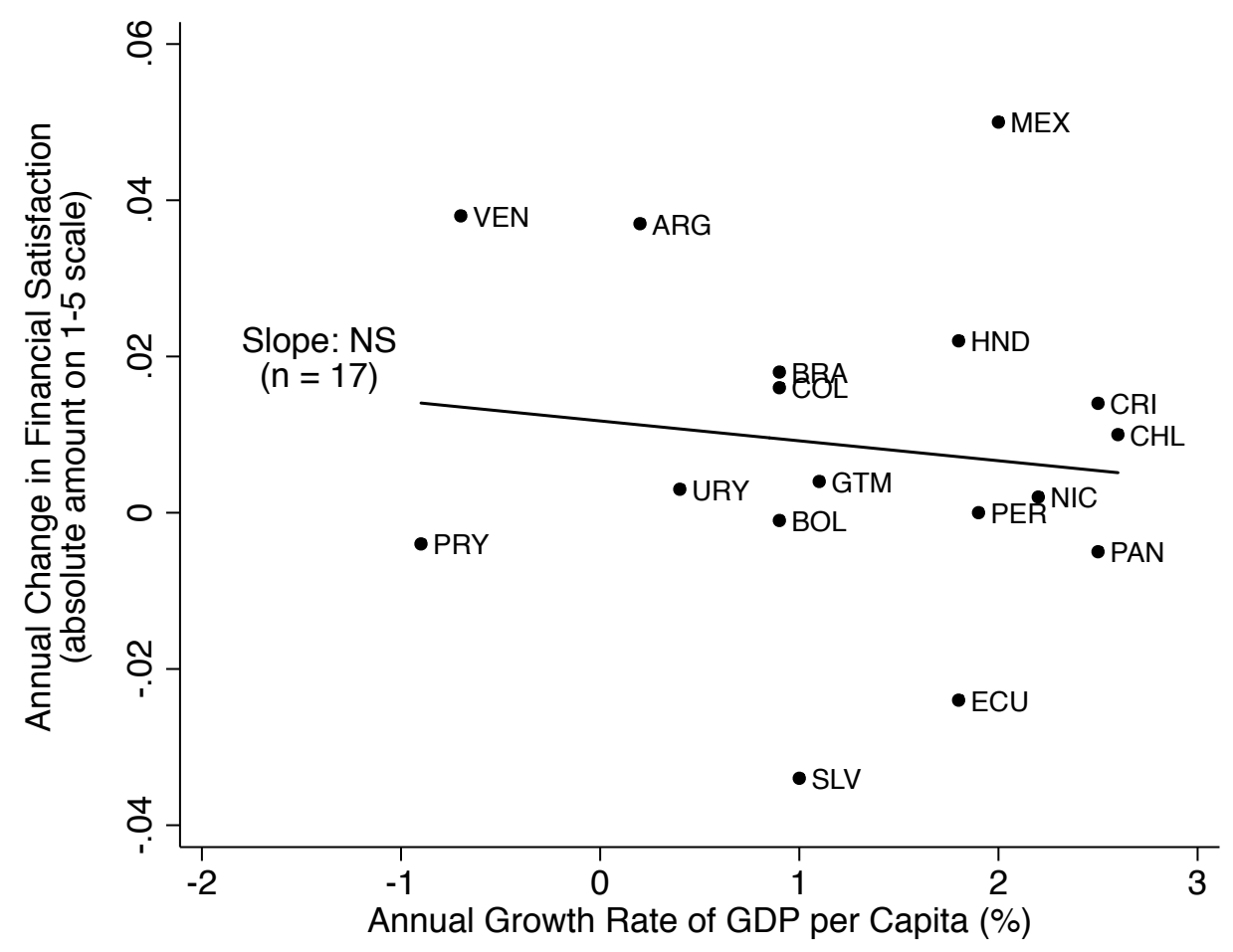

Source: Easterlin et al. 2010, Table S1. 
Figure 13.7. Mean Life Satisfaction, China, Six Series, c. 1990-2010

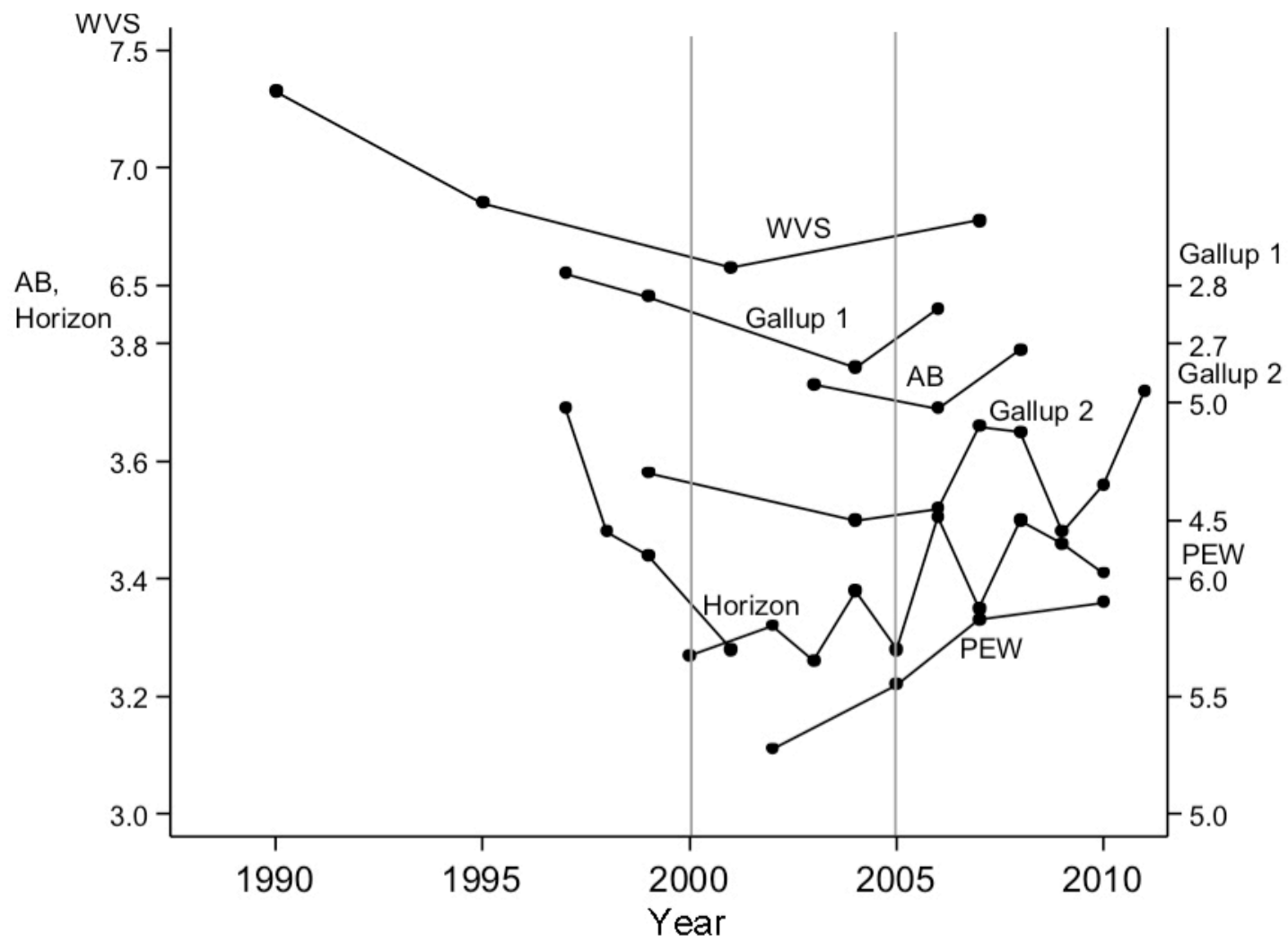

Source: Easterlin et al. 2012, Table S1. Scales on each side are for mean life satisfaction in specified survey. 
Figure 13.8. Mean Happiness, United States, 1973-2010

(vertical broken lines indicate period of Great Recession)

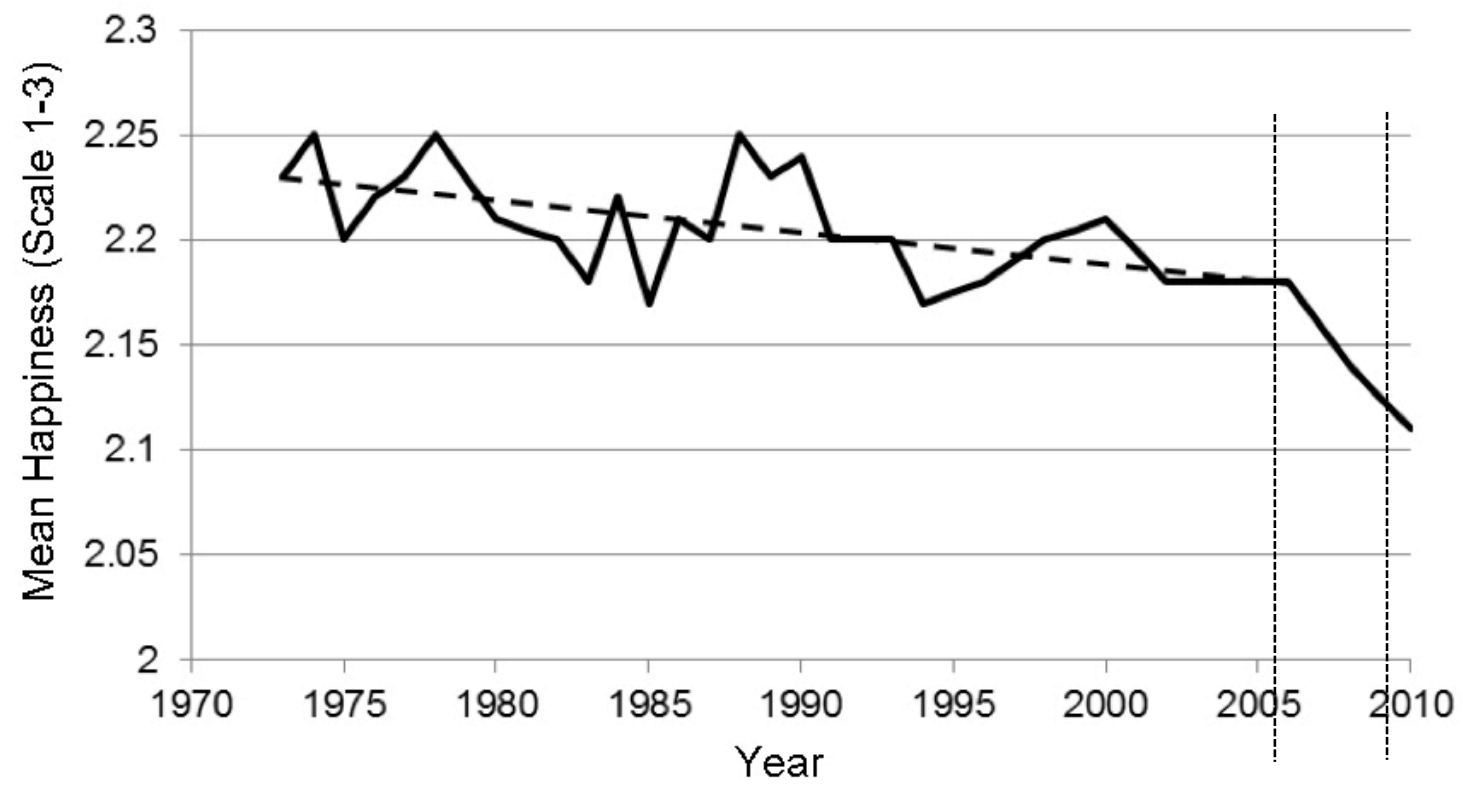

Source: NORC 2010. 
Figure 13.9. Mean Life Satisfaction and Annual Index of Real GDP, 3 Transition Countries, 1989-2005
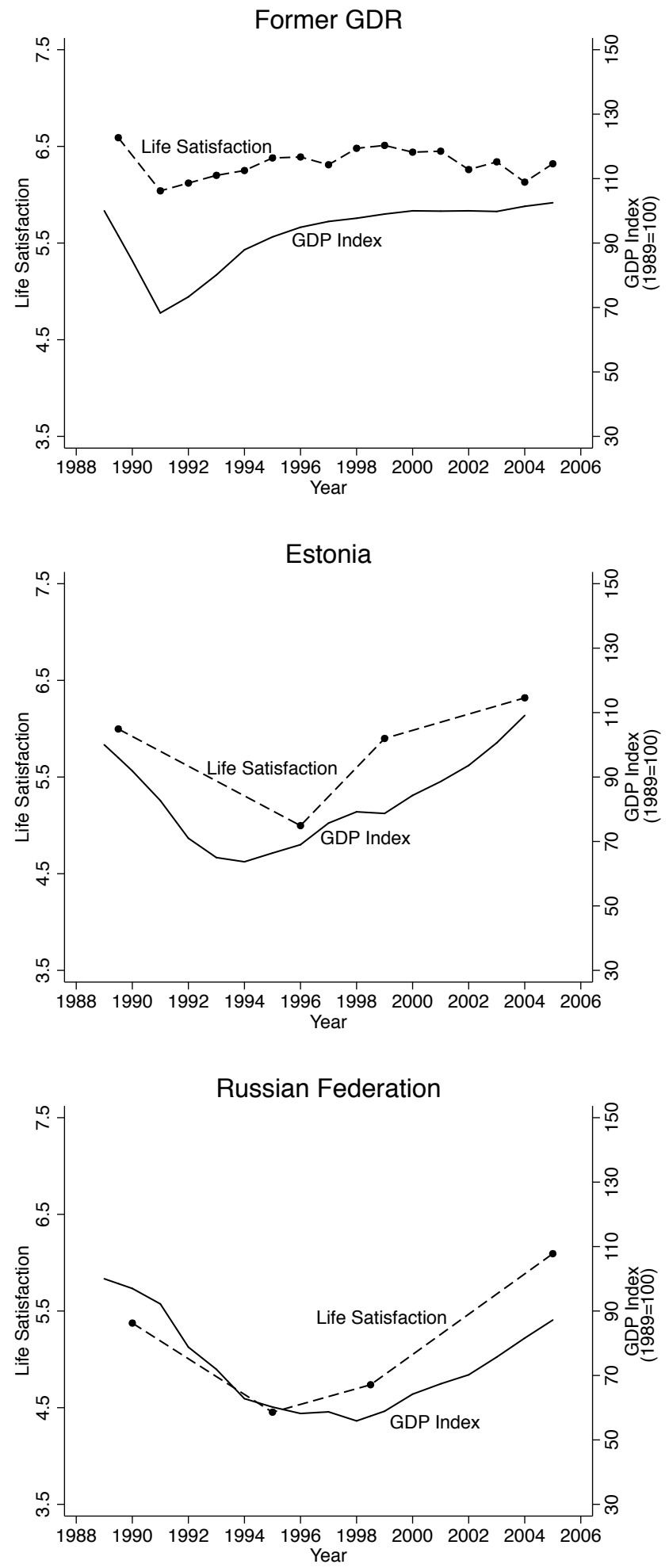

Source: Easterlin et al. 2010, Table S5. Life satisfaction is measured on a 1-10 scale. 
Figure 13.10. Mean Deviation from Trend in Financial Satisfaction and in Log GDP per Capita, 17 Latin American countries, Annually 1994-2006

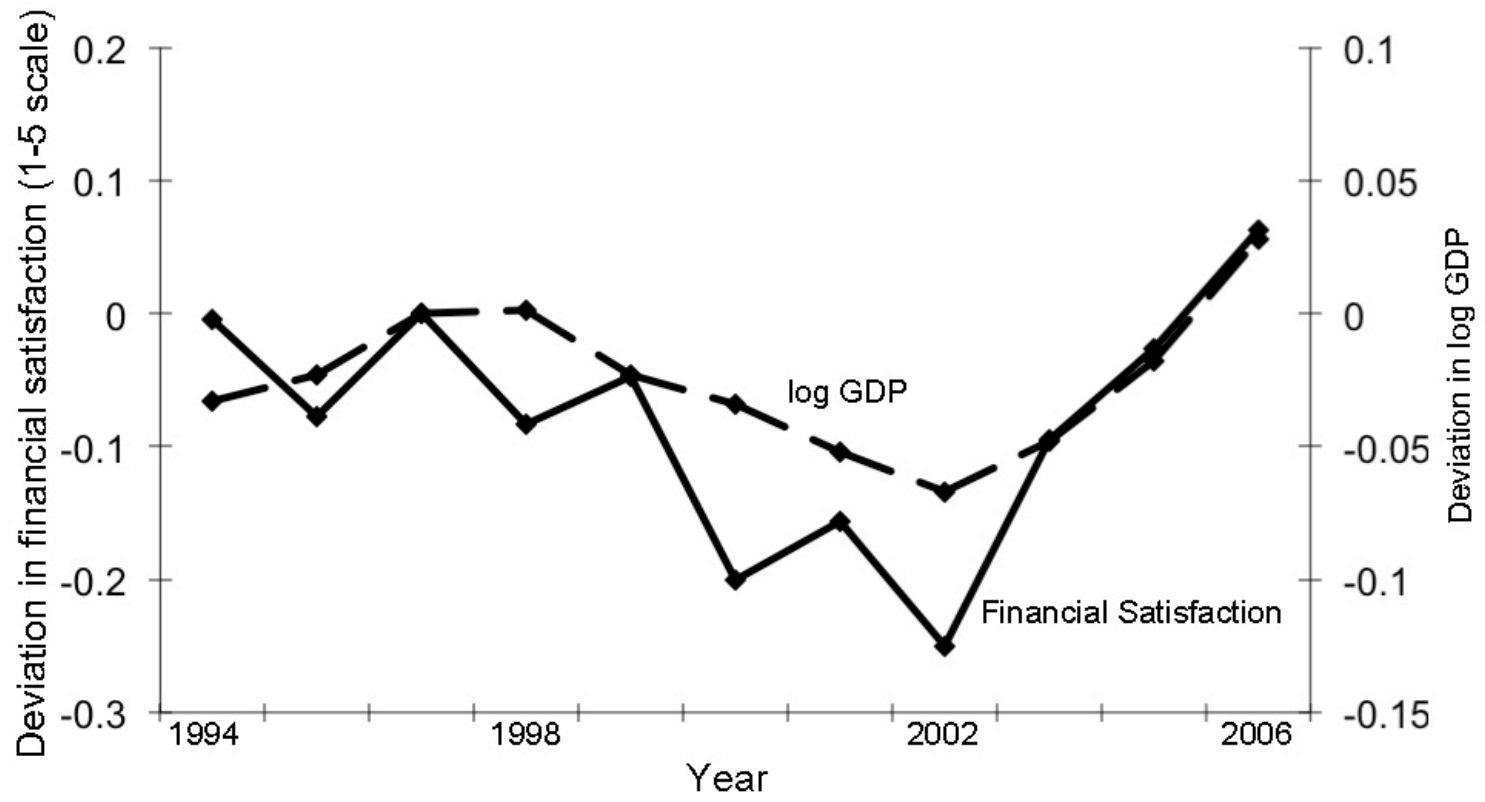

Source: Easterlin et al 2010, Tables S3, S4. 
Figure 13.11. Illustration of Short Term Fluctuations and Long Term Trends in Happiness and Income

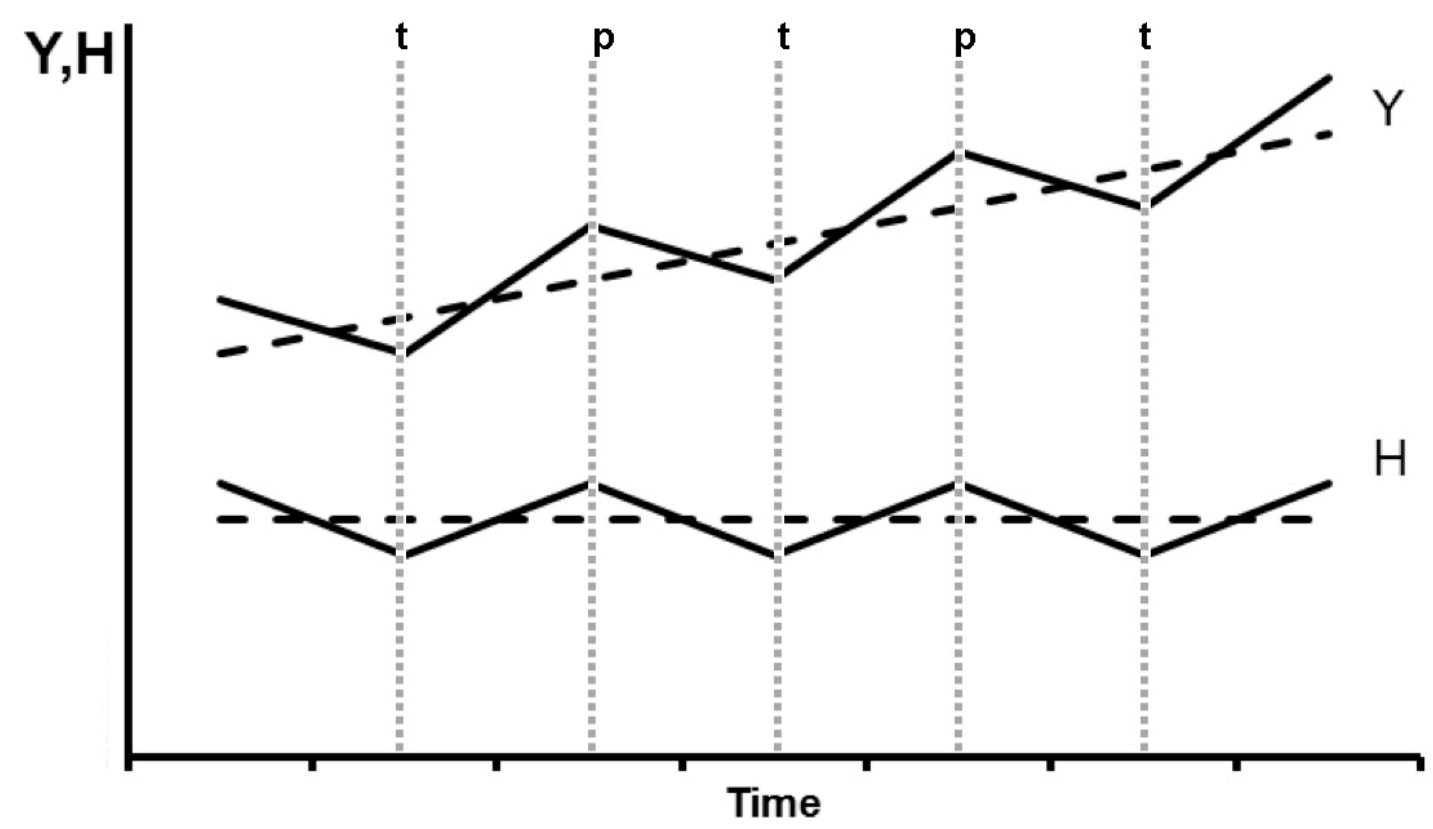

Happiness (H) and Income (Y) 
Figure 13.12. Long Term Relation: Illustration of Mistake (Confusing Short Term with Long Term Relation)

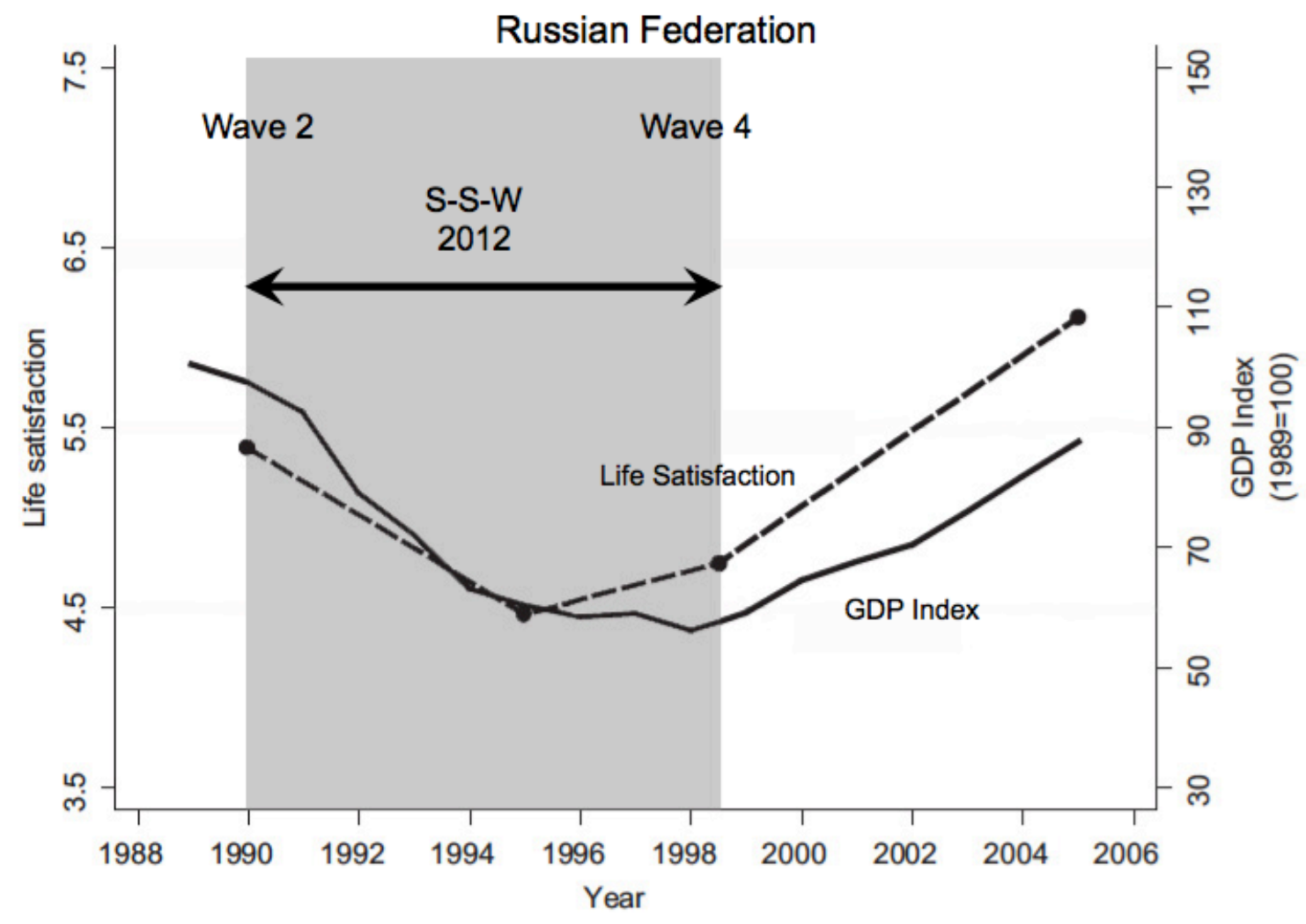

Source: Easterlin et al. 2010, Table S5. 
Figure 13.13. Long Term Relation: Illustration of Mistake (Confusing Short Term with Long Term Relation)

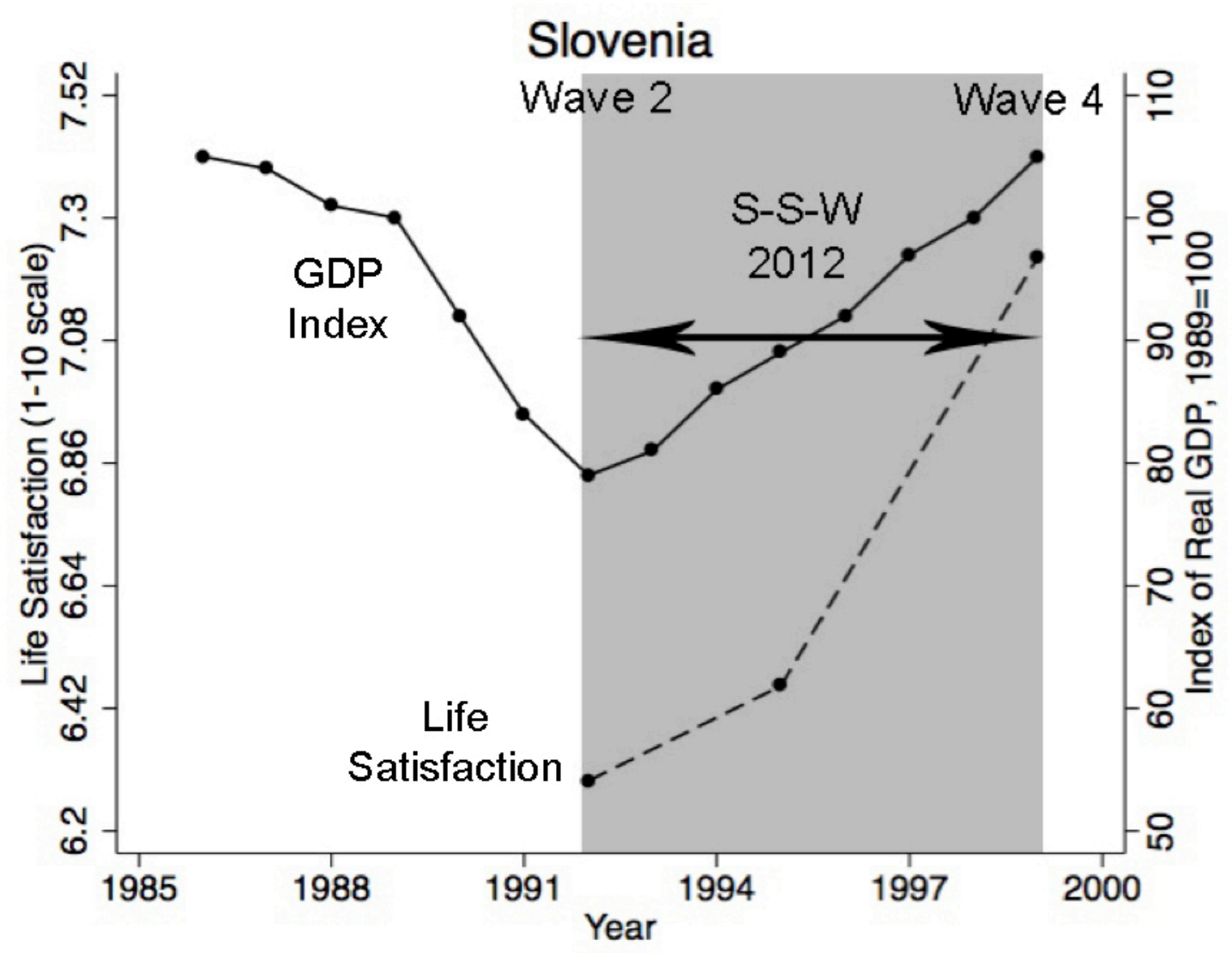

Source: Easterlin 2010, 91. 
Figure 13.14. Figure 13.2 with Single Value for Ireland, 1973-2007, Replaced by Three Sub-Period Values as in Sacks, Stevenson, and Wolfers 2012, Fig. 7

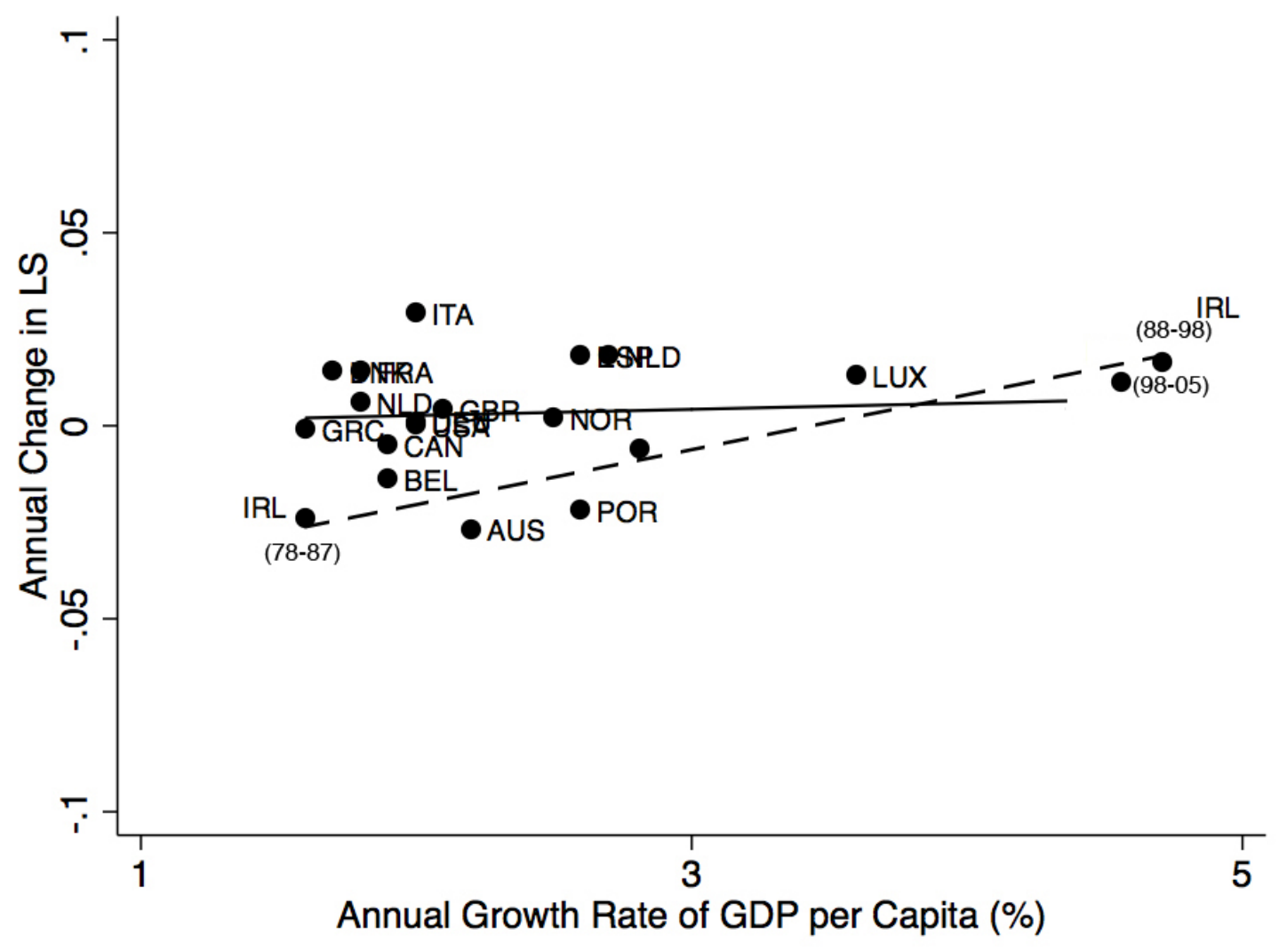


Easterlin, Richard A.

\section{Tables}

Table 13.1. Percentage of Black Population in Top Two Response Categories of Happiness and Life Satisfaction: South Africa, 1988-1995

\begin{tabular}{lccc} 
& 1988 & 1994 & 1995 \\
\hline Happiness & 32 & 80 & 39 \\
Life satisfaction & 37 & 86 & 45 \\
\hline
\end{tabular}

Source: South African Quality of Life Trends Study, kindly provided by Professor Valerie Møller. 